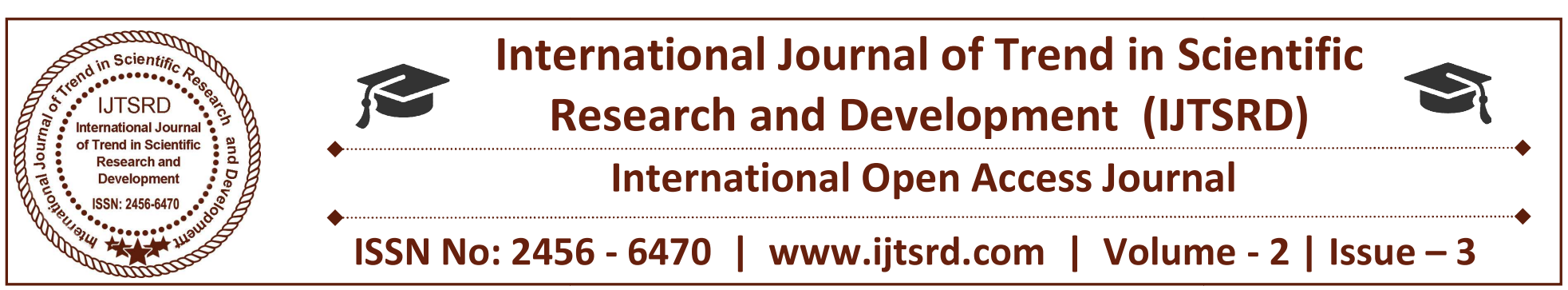

\title{
Solar Panel Dual Management System
}

\author{
Prof. Anand V. Sutar, Mr. Sumant Khetan, Mr. Akash kanase, Mr. Akash Karne, Mr. Akshay Irkar \\ Department of Electronics and Telecommunications, \\ Bharati Vidyapeeth College of Engineering, Belpada, Navi Mumbai, India
}

\begin{abstract}
As we know that use of solar energy is increasing day by day so there should be efficient use of solar energy. But due to pollution there is wastage of energy i.e. due to deposition of soil on solar panel .so there is always need to clean the solar panel in fixed days. but some time there is no desirable amount of soil deposited on panel which can decrease the power upto certain level but the company or organization has to pay the cleaner for his visit. And theft cases of solar panel are also increasing day by day. so our project is a solution for this.
\end{abstract}

Keywords: Energy Conservation, Photovoltaic Cell, Theft Prevention

\section{INTRODUCTION}

About $65 \mathrm{GW}$ of solar capacity is expected to be added globally in 2016, with Asian countries in the lead. Indian solar market appears in full bloom right now. But PhotoVoltaic systems have a potential performance problem of module soiling (dust or soot from local air pollution). It can reduce energy output significantly. Studies on module soiling show an average annual energy loss of 5\% for arrays that are not periodically cleaned. Also in recent years we have seen lots of Solar Panel Theft Cases in various countries. So there is a need for smart solution to tackle those problems. So my project proposes a solution for 1) Theft prevention and 2) Maintenance Indication of solar panel using LinkIt ONE and Sensors (Dust Sensor, Current Sensor and Accelerometer). The solution provides Theft prevention for Solar Panel and also indicates the time for maintenance, thereby preventing frequent visits

and save transportation cost as well as increases the usage and efficiency of Solar Panel.

1) Theft Prevention: To achieve this we use the GPS and GPRS features of LinkIt ONE Board with accelerometer. If the Panel moves or unauthorized activity occurs then there is change in axis value of accelerometer which will be detected by LinkIt ONE. It will process the data and notify the GPS location of Panel for tracking on webserver as well as on webapp.

2) Maintenance Indication: To achieve this function we use Dust, Voltage and Current Sensors. So when the deposition of dust on Panel increases the efficiency start to reduce, this can be monitored by LinkIt ONE using the sensor values. It will update this data on webserver which can be viewed to know the time for maintenance of Panel6

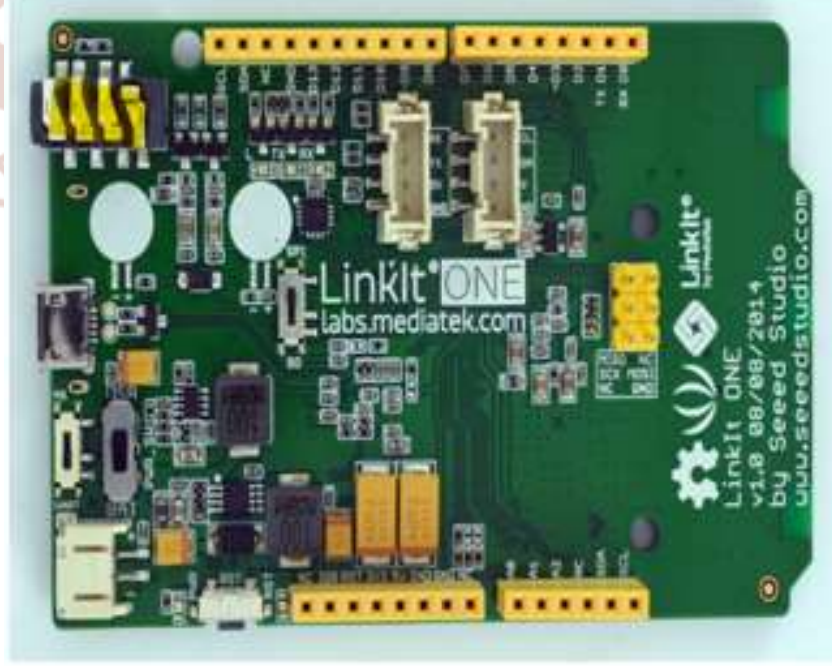

Fig 1: LinkIt One Board 


\section{RESEARCH ELABORATIONS}

\section{A. STUDY OF LINKIT ONE BOARD}

The Linkit ONE is a microcontroller developed and released by Mediatek and SeeedStudio. This was made for all the makers in this world for their wearables and IOT projects. The special thing about this chip is that it has Bluetooth, Wifi, GPS and GSM already present in a small package. It uses the same programming language as arduino making it easier to build and prototype projects. The pinout is somewhat similar to arduino so that all arduino sheilds are compatible with it. It also has an SD card slot, audio jack and separate sockets for I2c and UART. The following are the specifications of this board

\section{B. STUDY OF CURRENT SENSOR}

The ACS712 sensor read the current value and convert it into a relevant voltage value, The value that links the two measurements is sensitivity which - for $5 \mathrm{~A}$ model - has a typical value of $185 \mathrm{mV} / \mathrm{A}$. The sensor can measure positive and negative currents (range $-5 \mathrm{~A}$...5A), and power supply is $5 \mathrm{~V}$ for the sensor, and the middle sensing voltage is $2.5 \mathrm{~V}$ when no current. It measure both $\mathrm{AC}$ and $\mathrm{DC}$ current. LinkIt ONE analogRead() function outputs a value between 0 ( $0 \mathrm{~V}$ in input) and 1023 (5V in input) that is $0.0049 \mathrm{~V}$ for each increment. We will use the following formula to covert the $0 \sim 1023$ value to an ampere value.

\section{GROVE DUST SENSOR:}

A good indication of air quality is given by dust sensor in an environment by measuring the dust concentration. By counting the low pulse occupancy time in a given time unit, a particulate matter level is measured. Thus, thus sensor provides realiable data for air pourification and it is resonsible to $\mathrm{PM}$ of 1 micro metre diameter.

\section{GROVE ACCELORMETER:}

A indication of good air quality in environment is given by dust sensor by measuring the dust concentration. Now, by counting the low pulse occupancy time in given unit time particulate matter level in air is measured. Further this sensor provides reliable data for air purification and is response to PM of 1micrometer of diameter.

\section{HARDWARE IMPLEMENTATION}

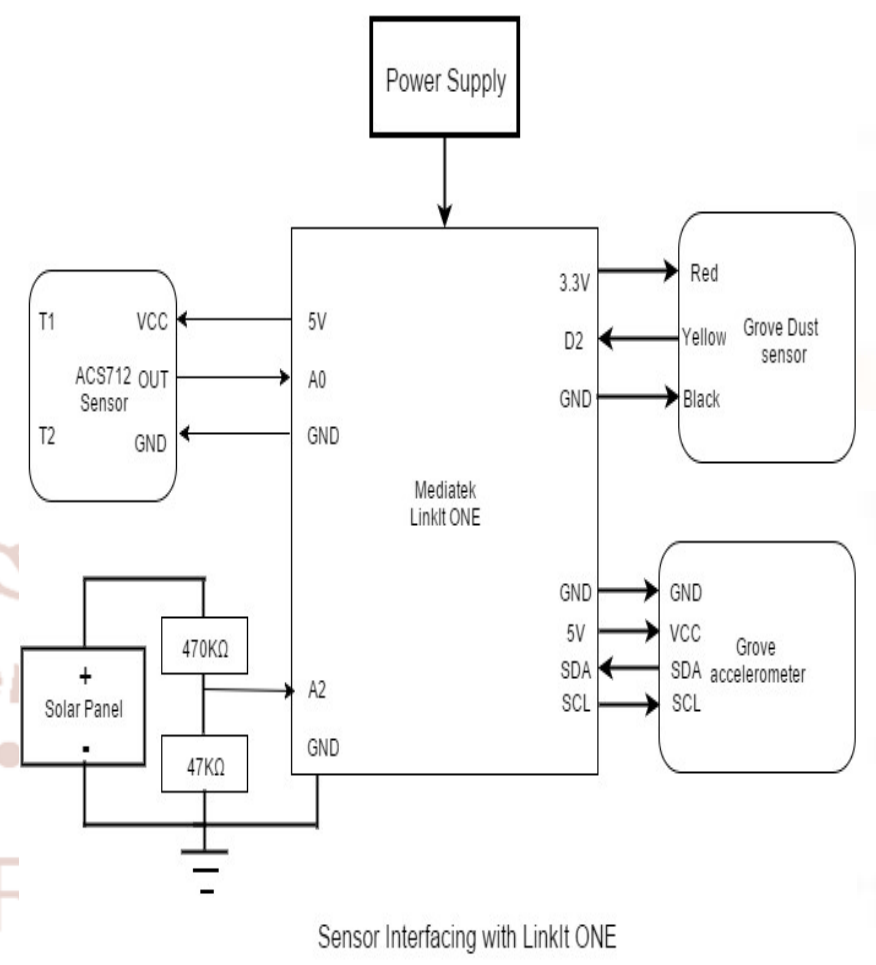

Fig 5: Hardware setup

\section{WORKING}

To achieve this we have use component listed above. Initially we have to interface all the sensors to the linkit board. as we know Since the analog pins of Linkit ONE is tolerant upto $5 \mathrm{~V}$ only, so we need to use voltage divider network to bring down voltage of panel within the range of Linkit ONE $(0-5 \mathrm{~V})$.in this we have use fan as load. The threshold value of current is decided by the user according to its use. this threshold is set in linkitboard. foreg 12.As soon as the dust deposition increases, The groove dust sensor starts sending data serially to the link it board. Due to the increase in the dust concentration there is change in value of current which is by current sensor. The current sensor converts it into releavant voltage value and send the data to linkit board serially. the power value is calculated and linkit board compares it with threshold value.and if it is less than it sends indication on webserver. Once panel moved or unauthorized access happens then device detects it using accelerometer sensor. After this device start sending only the GPS location of panel with battery for tracking and activity is indicated using alert variable on Ubidots. 
Activity or monitoring can also be viewed on webapp. Once alert is high then click on track button to trace device GPS location.

\section{CONCLUSION}

Thus our project performs the work of maintainence indicatin and theft prevention using mediatech linkit one board. The notification will be updated on ubidots web server.

\section{REFERENCE}

1. https://labs.mediatek.com/fileMedia/download/5f ed7907-b2ba-4000-bcb2-016a332a49fd

2. https://labs.mediatek.com/site/global/developer_t ools/mediatek_linkit/get-started/index.gsp

3. http://www.instructables.com/id/LinkIt-ONEGetting-Started-Guide/

4. http://www.seeedstudio.com/wiki/File:DigitalAc celerometer_ADXL345.zip 